\title{
Inpatient satisfaction and job satisfaction/stress of medical workers in a hospital with the 7:1 nursing care system (in which 1 nurse cares for 7 patients at a time)
}

\author{
Yuko Fujimura $\cdot$ Hideji Tanii $\cdot$ Kiyofumi Saijoh
}

Received: 15 June 2010/Accepted: 23 July 2010/Published online: 18 September 2010

(C) The Japanese Society for Hygiene 2010

\begin{abstract}
Objectives Inpatient satisfaction, job satisfaction/stress of medical workers, and hospital profitability under the 7:1 nursing care system (in which 1 nurse cares for 7 patients at a time) were compared with those under the 10:1 system at a hospital with the diagnosis procedure combination (DPC) payment system.

Methods A total of 202 inpatients discharged from the Departments of Cardiology and Metabolism completed an inpatient satisfaction questionnaire. A total of 108 medical workers were recruited to survey their job satisfaction/ stress and to estimate the effects of the DPC. The profits for 10 cardiac and metabolic diseases in 2008 were compared with those in 2007.

Results Mean inpatient satisfaction scores were around 4 ("somewhat satisfied") under both the 10:1 and 7:1 systems, and increased significantly to 4.14-4.38 under the 7:1 system. Excluding workload of physicians, the other stresses of physicians/nurses remained unaltered, as did their low job satisfaction. They estimated their understanding of the DPC as insufficient but felt that introducing the DPC neither shortened length of stay nor improved "the quality of medical/nursing care," regardless of the system. Total percentage profit increased to $1.17 \%$ in 2008 from $0.73 \%$ in 2007, whereas 7 of 10 diseases showed deficits in 2008.

Conclusions The 7:1 system was somewhat beneficial for inpatients but not always for medical worker quality of life
\end{abstract}

Y. Fujimura $\cdot$ H. Tanii $\cdot$ K. Saijoh ( $₫)$

Department of Hygiene, Kanazawa University School

of Medicine, 13-1 Takara-machi,

Kanazawa 920-8640, Japan

e-mail: saijohk@med.kanazawa-u.ac.jp
(QOL) or for hospital income, which are important to maintain high quality of medical/nursing care. It is important to further explore factors increasing QOL of medical workers and hospital income.

Keywords Inpatient satisfaction - Job satisfaction · Job stress $\cdot$ Medical workers - Diagnosis procedure combination payment system

\section{Introduction}

The Japanese health care system features universal health insurance coverage, free access, medical allowance in kind, and the fee-for-service (FFS) payment system by treatment-related group/prospective payment system (PPS). Recently, increases in annual medical expenditure have caused financial stringency in Japan [1]. The FFS may be a major cause of the recent increase in medical costs, because of its weak incentive for cost containment. Moreover, the rapid aging of society, stagnant economy, and high medical expenses due to advances in medical technology and equipment are exacerbating the increasing medical costs.

To improve these conditions, the diagnosis procedure combination (DPC) was introduced in 2003 at 82 specific function hospitals (80 university hospitals, 1 national cancer center, and 1 national cardiovascular center) and their acute inpatient care services. This new system was planned based on the concept of diagnosis-related groups (DRG)/PPS in the USA [1]. The DRG/PPS is a per-case payment system, and displays effects of shortening length of hospital stay (LOS), reducing total medical costs, and standardizing medical care [2-4]. The DPC in Japan was planned to manage the total medical costs, and adopted as a 
per-day payment system but not as a per-case payment system [1, 4]. The hospitals' adjusted fee, examinations (excluding endoscopy, intravascular catheter, and biopsy), diagnostic imaging, medication, and treatment with lower than 1,000 points (one point being equivalent to 10 yen) are calculated according to LOS. Even under the DPC, several procedures such as surgical procedures, anesthesia, biopsy, etc., are calculated by the FFS. Thus, the DPC is also expected to at least reduce total medical costs and shorten LOS in Japan.

These DPC hospitals supply the highest level of medical care in Japan and deal with patients with extremely serious conditions. Nonetheless, these hospitals are required to improve efficiency and cut costs in each division, e.g., outsourcing of supply processing and distribution system of medical materials, provision of hospital meals, and office staff, to cut down on personnel expenses. In fact, a decrease in profits has already been reported by surgery departments [5-7]. Despite their efforts and the existence of such reports, the adjustment coefficient to subsidize the benefit loss of DPC hospitals was abolished in 2010, and financial difficulties are anticipated. Thus, further cost reductions are required and may lead to a decrease in patient satisfaction and an increase in workload for medical staff.

Although such effects of the DPC have not been examined in detail, the nursing care system was changed in many DPC hospitals in 2008 to reduce the possible disadvantages of the DPC for patients; that is, the 10:1 nursing care system ( 1 nurse cares for 10 patients at a time) was changed to the 7:1 nursing care system (1 nurse cares for 7 patients at a time). This alteration may increase patient satisfaction and reduce workload of nurses, and introduce extra subsidization to a hospital. However, it requires an increase in the number of nurses and forces the hospital to outlay further expenditure.

In the present study, the utility of the 7:1 system was evaluated in terms of satisfaction of inpatients and job satisfaction/stress of medical workers in comparison with the 10:1 system. Medical workers' estimation of the DPC's effects on medical/nursing care and the profitability of the hospital under both systems were also evaluated. This approach is important for implementing total quality management (TQM) [8] to maintain high quality of med$\mathrm{ical} /$ nursing care in DPC hospitals.

\section{Subjects and methods}

This study was composed of three types of survey: (1) inpatient satisfaction and job satisfaction/stress of medical workers, (2) medical workers' estimation of the effects of the DPC with the 10:1 and 7:1 systems, and (3) profit analysis of DPC/FFS.
Subjects

\section{Inpatient satisfaction}

A total of 202 inpatients, who were discharged from the Departments of Cardiology and Metabolism of a specific function hospital from January to December 2008, gave their written informed consent and responded to a selfadministered questionnaire. The 7:1 system was introduced in May 2008. These subjects were selected to be younger than 75 years old, were under nursing grade III and IV (i.e., not always serious), could read/write the questionnaire without any assistance, and were emotionally stable.

\section{Medical workers participated}

The survey was given twice to medical workers at a 50-bed ward for internal diseases. The first survey was in February 2008 under the 10:1 system. The second survey occurred after the introduction of the 7:1 system in October 2008 . Under the 10:1 system, a total of 50 medical workers (36 physicians, 14 nurses) responded with a $68.5 \%$ (overall) response rate $(70.6 \%$ physicians, $63.6 \%$ nurses). Under the 7:1 system, a total of 58 medical workers (33 physicians, 25 nurses) responded to this survey. The response rate was $74.4 \%$ (overall), being $67.4 \%$ for physicians and $86.2 \%$ for nurses. The purpose and procedure of this survey were explained to the subjects, and written informed consent was obtained from all subjects.

This study was approved by the ethics committee of the Kanazawa University School of Medicine.

\section{Inpatient satisfaction, and physical and mental health}

The Japanese version of the Short-Form 36-Item Health Survey (SF-36) [9] was used to examine the quality of life (QOL) of inpatients before hospitalization. The scores of each item were calculated by the norm-based score (mean 50.0).

Thereafter, we analyzed the inpatient satisfaction questionnaire to examine the satisfaction level with medical care and nursing care simultaneously, using the same 7 items: Explanation, Easiness of Consultation, Dealing with Patients, Reliability, Coping with Patients' Pain/Indisposition, Coping with Patients' Anxiety/Mental Care, and Satisfaction. Each scale item had five response items on a Likert-type 5-point scale: (5) "very satisfied," (4) "somewhat satisfied," (3) "neither satisfied nor dissatisfied," (2) "somewhat dissatisfied," and (1) "very dissatisfied." These 7 items were selected and modified with reference to a nationwide survey where medical quality, safety, and patient satisfaction of university hospitals were investigated in 2003 just after introduction of the DPC [10]. 
Moreover, satisfaction with Physical and Mental Recovery and Overall Satisfaction during hospitalization were also addressed with the same five response scales. Satisfaction with regard to medical care and nursing care included 7 items, and the summed score was divided by 7 to facilitate comparison against scores for satisfaction with Physical and Mental Recovery and Overall Satisfaction.

\section{Job satisfaction/stress of medical workers}

A previous nationwide survey examined total job satisfaction alone [10]. However, to determine the effects of the 7:1 system, a questionnaire in terms of the physicians' and nurses' estimation of their Working Hours, Income, Number of Physicians in the Ward, and Number of Nurses in the Ward was utilized. Each scale item had five response items on a Likert-type 5-point scale: (5) "many," (4) "somewhat many," (3) "neither many nor few," (2) "somewhat few," and (1) "few."

We also applied the DPC-specific questionnaire consisting of 11 items regarding their estimation of the desired effects, efficiencies, and results after introducing the DPC (Fig. 1). Each scale item had five response items on a Likert-type 5-point scale: (5) "totally agree," (4) "somewhat agree," (3) "neither agree nor disagree," (2) "somewhat disagree," and (1) "disagree."

Levels of mental and physical stress were examined using the Simplified Job Stressor Questionnaire (SJSQ), which consisted of 57 questions with four response items on a Likert-type 4-point scale: (4) "totally agree,"

a Job Satisfaction
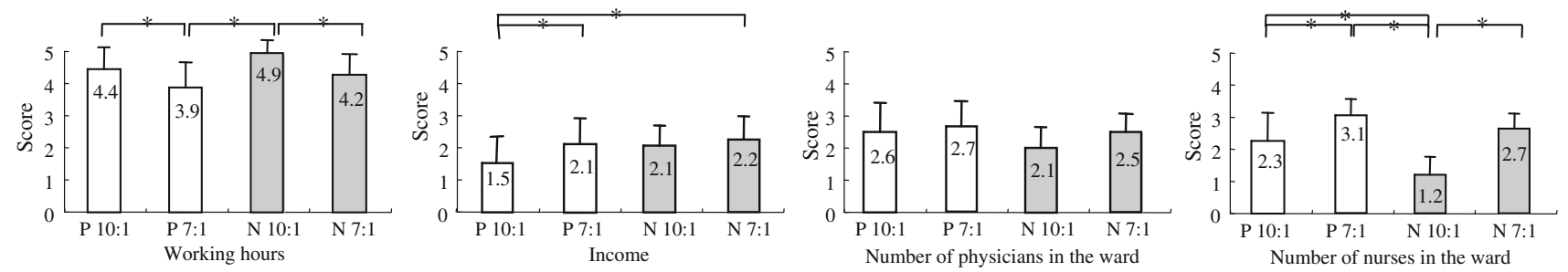

b Under the DPC,
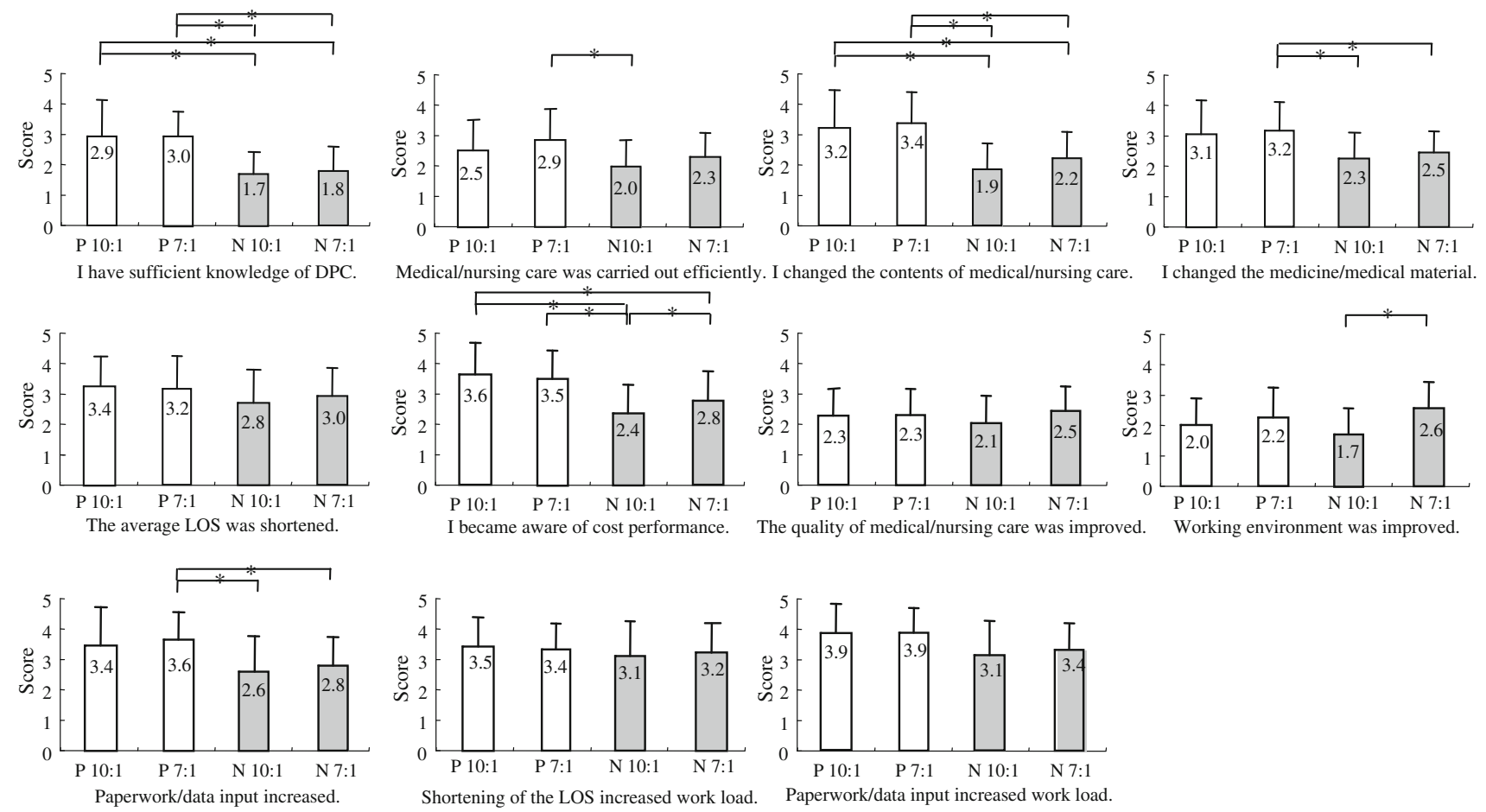

Fig. 1 Estimation of job satisfaction and effects of DPC by physicians (P) and nurses (N) under the 10:1 (1) and 7:1 (2) systems. Working status (a) was scored using a Likert-type 5-point scale: (5) "many," (4) "somewhat many," (3) "neither many nor few," (2)"somewhat few," and (1) "few." Effects after the introduction of DPC (b) were scored

as: (5) "totally agree," (4) "somewhat agree," (3) "neither agree nor disagree," (2) "somewhat disagree," and (1) "disagree." The differences in scores among groups were as analyzed with one-way ANOVA following Scheffe's post hoc test $(* P<0.05)$ 
(3) "somewhat agree," (2) "somewhat disagree," and (1) "disagree" [11]. Stressors of work were judged with these subscales: Workload, Control, Personal Relations, Conformity, and Support by Coworkers/Supervisor and responses to stress with Mental Stress and Physical Stress. Those who required care due to high stress in each subscale were judged according to each scoring standard [11].

\section{Profit analysis}

Profit data for 2007 and 2008 were obtained from the Division of Medical Information. We compared the DPC points and profits (DPC-FFS) of 10 cardiac and metabolic diseases in 2007 under the 10:1 system with those in 2008, the period after introduction of the 7:1 system. As the 7:1 system was introduced in May 2008, we directly compared profits for the corresponding 8-month period, i.e., MayDecember, in 2007 and 2008.

\section{Statistical analysis}

Characteristics of inpatients, SF-36, and satisfaction data were evaluated using Student's $t$ test. Inpatient satisfaction was also analyzed by exploratory factor analysis using principal axis factoring with rotation by promax with Kaiser normalization and by multiple regression analysis. The characteristics of medical workers and the results of the survey regarding job satisfaction and the DPC-specific items were evaluated with either Student's $t$ test or by oneway analysis of variance (ANOVA) following Scheffe's post hoc test. The results of the SJSQ were evaluated using Fisher's exact test.

\section{Results}

Characteristics of inpatients and their QOL

before hospitalization and satisfaction after admission

The 202 inpatients in the study included almost twice as many men $(n=134)$ as women $(n=68)$ (Table 1$)$. Mean age and LOS were not significantly different. All SF-36 scores before hospitalization were lower than the national mean (50), and scores were generally poorer for women than for men. Although the scores for General and Mental Health Perception and Social Functioning were not different between men and women, differences in Physical Functioning, Role-Physical, Body Pain, Vitality, and RoleEmotional were statistically significant. In summary scores, Physical Component Summary was also significantly lower for women than for men. Means of satisfaction scores were around 4 regardless of subscale, and there were no significant differences between men and women.
Satisfaction level was almost the same as the nationwide survey, where more than $90 \%$ of patients scored more than 4 for Overall Satisfaction [10]. As expected, the group with LOS $\geq 15$ had higher mean age and lower SF-36 scores than the LOS $<15$ group. It is also not surprising that the mean satisfaction for Physical and Mental Recovery of the LOS $\geq 15$ group did not reach "somewhat satisfied" and was significantly lower than that of LOS $<15$ group. Comparing the 10:1 system inpatients with the 7:1 system inpatients, the 7:1 inpatients showed greater satisfaction in all subcategories, which ranged as high as 4.14-4.38. Differences between groups divided according to age using the mean age as cutoff were not always significant, as well as the differences between the Cardiology group and Metabolism group (data not shown).

Principal axis factoring extracted two factors related to patient satisfaction with high Cronbach's alpha coefficients of 0.95 and 0.94 , respectively (Table 2). The first factor consisted mainly of Nursing Care, and Reliability and Satisfaction had extremely high factor scores (both 0.92), followed by Coping with Patients' Anxiety/Mental Care and Coping with Patients' Pain/Indisposition. The score for Dealing with Patients was lower than 0.80 , and that for Easiness of Consultation was as low as 0.63 . The second factor consisted of Medical Care. Dealing with Inpatients showed high factor scores $(>0.9)$, as did Reliability, which was followed by Explanation, Coping with Patients' Anxiety/Mental Care, and Easiness of Consultation. The score for Satisfaction was only 0.68, and Coping with Inpatients' Pain/Indisposition had a low factor score. Multiple regression analysis extracted the formula: Overall Satisfaction $=$ $0.36 \times$ Nursing Care $+0.23 \times$ Medical Care $+0.25 \times$ Physical/Mental Recovery. All coefficients were statistically significant $(P<0.01)$, and the coefficient for Nursing Care was higher than the others.

\section{Characteristics of physicians and nurses}

Mean age of both physicians and nurses was around 30 years, which was due to this being a training hospital for interns (Table 3). This was also true for their generally short working years both after acquisition of their licenses and in this hospital. Young physicians were rotated specifically to several other hospitals, so that their working years were limited. Physicians under the 10:1 system worked for $67.2 \pm 15.7 \mathrm{~h} /$ week, which was significantly longer than nurses regardless of the system. They were still working over $60 \mathrm{~h} /$ week under the $7: 1$ system, but the difference compared with nurses was not always statistically significant. Physicians required $3.9 \pm 2.3 \mathrm{~h} /$ day for paperwork, which was significantly longer than that required by nurses (around twice as long under both systems). Aside from nurses who were working under the 


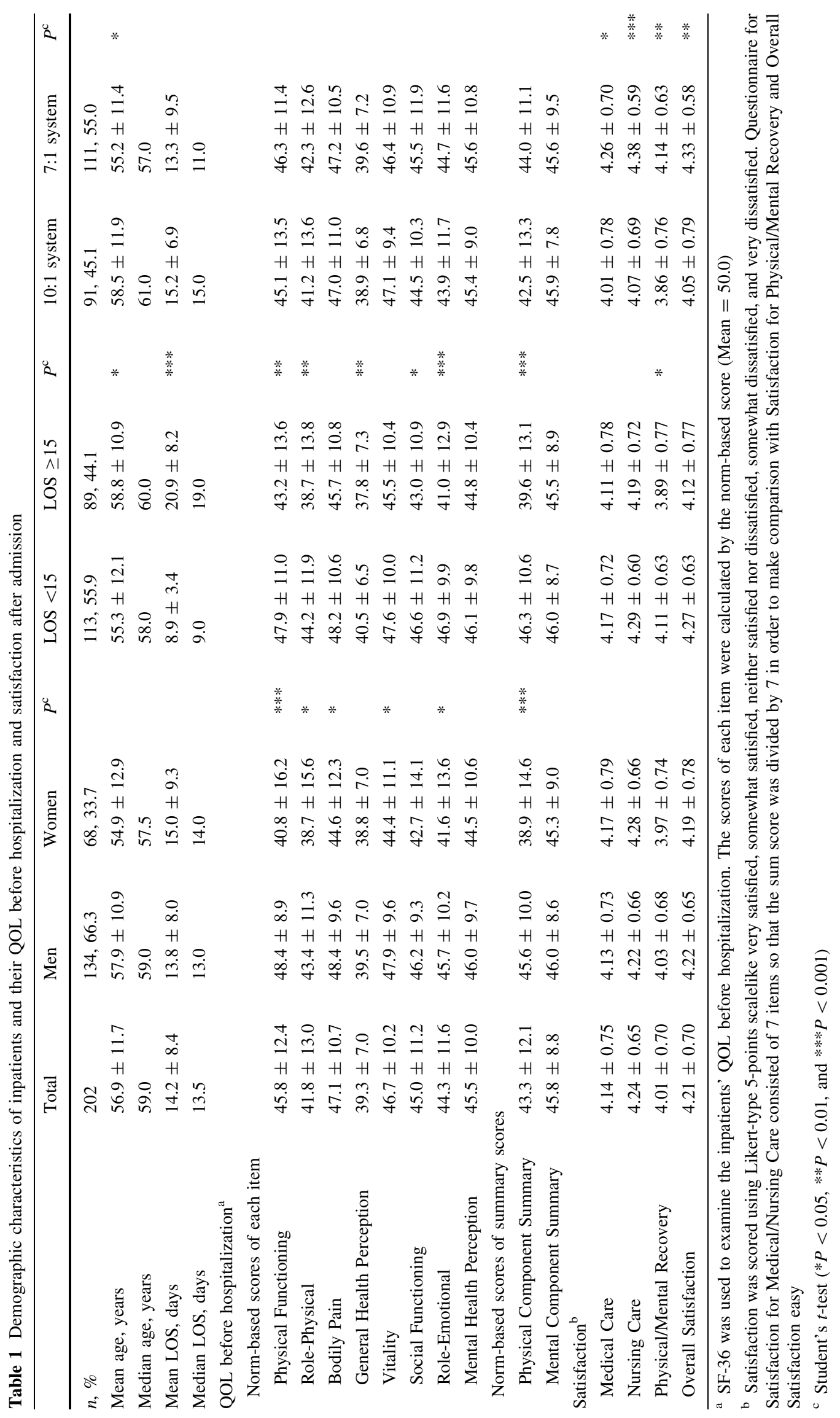


3-shift system, physicians were required to perform night duty twice a month and to work at nearby hospitals for around 9 days/month. Physicians working for university hospitals are also responsible for maintaining community health, especially for hospitals in rural areas. This was similar to previous Japanese surveys [12-14].

Table 2 Factor analysis of inpatient satisfaction

\begin{tabular}{lrr}
\hline Impatient satisfaction & Factor 1 & Factor 2 \\
\hline Nursing Care & & \\
Reliability & $\mathbf{0 . 9 2}$ & -0.04 \\
Satisfaction & $\mathbf{0 . 9 2}$ & -0.01 \\
Coping with Patients' Anxiety/Mental Care & $\mathbf{0 . 8 7}$ & -0.09 \\
Coping with Patients' Pain/Indisposition & $\mathbf{0 . 8 5}$ & -0.01 \\
Explanation & $\mathbf{0 . 8 1}$ & 0.06 \\
Dealing with Patients & $\mathbf{0 . 7 8}$ & 0.11 \\
Easiness of Consultation & $\mathbf{0 . 6 3}$ & 0.29 \\
Medical Care & & \\
Reliability & -0.07 & $\mathbf{0 . 9 9}$ \\
Dealing with Patients & -0.06 & $\mathbf{0 . 9 6}$ \\
Explanation & -0.06 & $\mathbf{0 . 8 4}$ \\
Coping with Patients' Anxiety/Mental Care & 0.08 & $\mathbf{0 . 8 3}$ \\
Easiness of Consultation & 0.09 & $\mathbf{0 . 8 0}$ \\
Satisfaction & 0.16 & $\mathbf{0 . 6 8}$ \\
Coping with Patients' Pain/Indisposition & 0.36 & $\mathbf{0 . 3 9}$ \\
Cronbach's $\alpha$ & 0.95 & 0.94 \\
\hline
\end{tabular}

Factors 1 and 2 were extracted by principal axis factoring with initial eigenvalues of 8.99 and 1.67, respectively. Thereafter, rotation was made using promax with Kaiser normalization. Interfactor correlation was 0.68
Job satisfaction/stress of physicians and nurses

Under the 10:1 system, nurses judged that their working hours were longer than physicians did, but this difference was not statistically significant (Fig. 1a). Both physicians and nurses under the 7:1 system judged that their working hours were significantly shorter than those under the 10:1 system; however, their real working hours were unaltered (Table 3). In fact, even in the 7:1 system, the SJSQ indicated that both physicians and nurses had stress problems, especially related to Workload. That is, under the 10:1 system, a high rate of physicians (83.3\%) and nurses (92.9\%) showed high level of stress for Workload and required care. A survey of approximately 25,000 workers indicated that around 10\% of them are categorized as having high stress for Workload [11], and therefore these rates were extremely high. The rate of physicians with high stress for Workload was significantly reduced under the 7:1 system to $63.6 \%$, but the rate for nurses was unaltered. Although the difference was not always significant, the rate of physicians with high stress for Control was almost twice that of nurses and more than 10 times as much as the survey [11] under the 10:1 system. Under the 7:1 system, it was reduced but was still higher than that for nurses. The rates for Personal Relations, Conformity, and Support by Coworkers/Supervisor were relatively low but were not altered from those under the 10:1 system. Approximately $20 \%$ of physicians and nurses had high Mental and Physical Stress under the 10:1 system. Under the 7:1 system, the rates for high Physical Stress for both physicians and nurses were slightly reduced, but these differences were not statistically significant, whereas that for high Mental Stress remained unchanged.

Table 3 Characteristics and working status of physicians and nurses under the 10:1 and 7:1 systems

\begin{tabular}{|c|c|c|c|c|c|c|c|c|c|c|c|}
\hline & \multirow[t]{2}{*}{ Age } & \multicolumn{2}{|c|}{ Working years $^{\mathrm{a}}$} & \multicolumn{2}{|l|}{ Working years $^{\mathrm{b}}$} & \multicolumn{2}{|l|}{ Working hours } & \multicolumn{2}{|l|}{ Working hours } & \multicolumn{2}{|c|}{ Intermission } \\
\hline & & $\mathrm{y}$ & $\mathrm{e}$ & $\mathrm{y}$ & e & $\mathrm{h} /$ week & e & $\mathrm{h} /$ day & f & $\mathrm{h} /$ day & e \\
\hline \multicolumn{12}{|l|}{ Physicians } \\
\hline The $10: 1$ system $n=36$ & $32.3 \pm 5.1$ & $7.8 \pm 4.9$ & n.s & $2.9 \pm 2.7$ & n.s & $67.2 \pm 15.7$ & 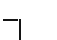 & $12.1 \pm 2.4$ & n.s & $0.8 \pm 0.2$ & 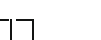 \\
\hline $\begin{array}{l}\text { The 7:1 system } n=33 \\
\text { Nurses }\end{array}$ & $34.6 \pm 5.4-$ & $9.6 \pm 5.2$ & & $5.0 \pm 4.7$ & & $61.1 \pm 15.7$ & $* *$ & $11.5 \pm 2.0$ & & $0.8 \pm 0.3$ & $* *$ \\
\hline The $10: 1$ system $n=14$ & $33.3 \pm 8.6$ & $10.9 \pm 8.3$ & & $10.0 \pm 8.2$ & & $51.9 \pm 9.3]$ & & $\mathrm{c}$ & & $0.6 \pm 0.2$ & I \\
\hline \multirow[t]{3}{*}{ The 7:1 system $n=25$} & $28.7 \pm 8.1-$ & $7.0 \pm 8.1$ & & $5.8 \pm 7.9$ & & $52.1 \pm 11.8$ & 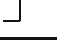 & & & $0.6 \pm 0.2$ & \lrcorner \\
\hline & Paperwork & Day off & & No of night duty & & Working day ${ }^{\mathrm{d}}$ & & Society activity & & Labor unior & $n$ activity \\
\hline & $\mathrm{h} /$ day $\quad \mathrm{e}$ & days/month & e & No/months & $\mathrm{f}$ & days/month & $\mathrm{f}$ & days/month & f & $\mathrm{h} /$ month & e \\
\hline \multicolumn{12}{|c|}{ Physicians } \\
\hline The $10: 1$ system $n=36$ & $3.9 \pm 2.3-$ & $4.7 \pm 2.3$ & - & $2.0 \pm 1.4$ & n.s & $8.8 \pm 3.2$ & n.s & $3.8 \pm 1.9$ & & $0.0 \pm 0.2$ & n.s \\
\hline The 7:1 system $n=33$ & $3.9 \pm 2.3$ & $6.1 \pm 2.1$ & $-l_{*}$ & $2.0 \pm 1.5$ & & $9.0 \pm 3.5$ & & $3.9 \pm 2.3$ & & $0.1 \pm 0.3$ & \\
\hline Nurses & & & & & & & & & & & \\
\hline The $10: 1$ system $n=14$ & $2.1 \pm 1.5]$ & $8.1 \pm 0.5$ & & $\mathrm{c}$ & & $\mathrm{c}$ & & $0.6 \pm 1.4$ & - & $0.1 \pm 0.3$ & \\
\hline The $7: 1$ system $n=25$ & $1.7 \pm 0.9$ & $8.1 \pm 0.3$ & & & & & & $0.6 \pm 1.1$ & \lrcorner & $0.1 \pm 0.3$ & \\
\hline
\end{tabular}

Working years a after the acquisition of a license and ${ }^{b}$ in this hospital. ${ }^{\mathrm{c}}$ Nurses were working under the 3-shift system so that their working h/day, no. of night duty/month, and working days/month were the same under both systems. ${ }^{\mathrm{d}}$ Working days in another hospitals. Statistical differences were analyzed either by ${ }^{\mathrm{e}}$ one-way ANOVA followed by Scheffe test as a post hoc test or ${ }^{\mathrm{f}}$ Student's $t$ test $(* P<0.05)$ 
Satisfaction with income was generally low because they belonged to a National University Hospital (Fig. 1a). In the nationwide survey [10], more than $50 \%$ of both physicians and nurses scored total satisfaction lower than 3 , and so the low levels of satisfaction with Income as well as with Working Hours observed here are not surprising. Both physicians and nurses recognized that Number of Nurses, but not Number of Physicians in the Ward, significantly increased under the 7:1 system compared with the 10:1 system. Of course, this is the effect of alteration from the 10:1 to $7: 1$ system. However, their recognition was still around 3, i.e., "neither many nor few."

Estimation of the DPC by physicians and nurses

When their understanding and estimation of the DPC was examined, the physicians' score for "having sufficient knowledge" was around 3, and that for nurses was lower than 2; the scores for nurses were significantly lower than those for physicians under both systems (Fig. 1b). Both physicians and nurses had a score for "Medical/nursing care was carried out efficiently" of $<3$. The scores for both "I changed the contents of medical/nursing care" and "I changed medicine/medical material" were higher than 3 for the physicians and lower than 2 for the nurses, regardless of the system. A similar tendency was observed for "I became aware of cost performance" and "Paperwork/data input increased." In fact, physicians spent approximately $4 \mathrm{~h}$ /day on paperwork/data input (Table 3 ). Both physicians and nurses scored "Paperwork/data input increased work load of medical/nursing care" higher than 3 , regardless of the system; in fact, the physicians' score was as high as 3.9. The effect of the DPC on shortening the LOS was recognized as around 3 by both physicians and nurses, irrespective of the system. However, both physicians and nurses scored "Shortening of the LOS increased the work load of medical/nursing care" higher than 3, regardless of the system. There was no improvement in "the quality of medical/nursing care" or "the working environment" under the DPC, being scored by both physicians and nurses as around 2, even though the nurses' score in the 7:1 system was higher than that in the 10:1 system (Table 4).

The profits of the hospital

When the profits of the hospital in 2007 under the 10:1 system and 2008 under the 7:1 system were compared, total percentage profit increased to $1.17 \%$ in 2008 from $0.73 \%$ in 2007 (Table 5). However, in 2007, deficits were observed only in acute myocardial infarction, valvular heart disease, and arteriosclerosis obliterans, whereas seven

Table 4 Number and proportion of physicians/nurses who required care due to high stress

\begin{tabular}{|c|c|c|c|c|c|c|c|c|c|c|}
\hline \multirow[t]{3}{*}{ Factor (subscales) } & \multirow{3}{*}{$\begin{array}{l}\text { With high stress } \\
\text { required care }\end{array}$} & \multicolumn{4}{|c|}{ 1st stage } & \multicolumn{4}{|c|}{ 2nd stage } & \multirow[t]{3}{*}{$P^{\mathrm{a}}$} \\
\hline & & \multicolumn{2}{|c|}{ Physicians, $n=36$} & \multicolumn{2}{|c|}{ Nurses, $n=14$} & \multicolumn{2}{|c|}{ Physicians, $n=33$} & \multicolumn{2}{|c|}{ Nurses, $n=25$} & \\
\hline & & $N$ & $\%$ & $N$ & $\%$ & $N$ & $\%$ & $N$ & $\%$ & \\
\hline \multicolumn{11}{|l|}{ Stressor of work } \\
\hline \multirow[t]{2}{*}{ Workload } & + & 30 & 83.3 & 13 & 92.9 & 21 & 63.6 & 24 & 96.0 & $<0.01$ \\
\hline & - & 6 & 16.7 & 1 & 7.1 & 12 & 36.4 & 1 & 4.0 & \\
\hline \multirow[t]{2}{*}{ Control } & + & 24 & 66.7 & 5 & 35.7 & 17 & 51.5 & 10 & 40.0 & 0.11 \\
\hline & - & 12 & 33.3 & 9 & 64.3 & 16 & 48.5 & 15 & 60.0 & \\
\hline \multirow[t]{2}{*}{ Personal Relations } & + & 12 & 33.3 & 1 & 7.1 & 10 & 30.3 & 4 & 16.0 & 0.16 \\
\hline & - & 24 & 66.7 & 13 & 92.9 & 23 & 69.7 & 21 & 84.0 & \\
\hline \multirow[t]{2}{*}{ Conformity } & + & 7 & 19.4 & 0 & 0.0 & 5 & 15.2 & 2 & 8.0 & 0.28 \\
\hline & - & 29 & 80.6 & 14 & 100.0 & 28 & 84.8 & 23 & 92.0 & \\
\hline \multirow[t]{2}{*}{ Support by Coworkers/Superior } & + & 3 & 8.3 & 0 & 0.0 & 3 & 9.1 & 1 & 4.0 & 0.75 \\
\hline & - & 33 & 91.7 & 14 & 100.0 & 30 & 90.9 & 24 & 96.0 & \\
\hline \multicolumn{11}{|l|}{ Response to Stress } \\
\hline \multirow[t]{2}{*}{ Mental Stress } & + & 7 & 19.4 & 3 & 21.4 & 6 & 18.2 & 5 & 20.0 & 0.99 \\
\hline & - & 29 & 80.6 & 11 & 78.6 & 27 & 81.8 & 20 & 80.0 & \\
\hline \multirow[t]{2}{*}{ Physical Stress } & + & 7 & 19.4 & 3 & 21.4 & 4 & 12.1 & 4 & 16.0 & 0.79 \\
\hline & - & 29 & 80.6 & 11 & 78.6 & 29 & 87.9 & 21 & 84.0 & \\
\hline
\end{tabular}

The level of Mental and Physical Stress was examined by the simplified job stressor questionnaire [11], consisting of 57 questions with four response items (Likert-type 4-point scale): "totally agree," "somewhat agree," "somewhat disagree," and "disagree." Those who required care due to high stress were judged according to the protocol

${ }^{a}$ Fisher's exact test 
Table 5 Profitability of the hospital for 10 cardiac and metabolic diseases under the 10:1 and 7:1 systems

\begin{tabular}{|c|c|c|c|c|c|c|}
\hline \multirow[t]{2}{*}{ DPC code (disease) } & \multicolumn{3}{|c|}{2007 under the $10: 1$ system } & \multicolumn{3}{|c|}{2008 under the $7: 1$ system } \\
\hline & DPC (points) & Profits (points) & Profits $(\%)$ & DPC (points) & Profits (points) & Profits $(\%)$ \\
\hline 050030 (acute myocardial infarction) & $9,485,142$ & $-65,882$ & -0.69 & $15,217,670$ & $-84,707$ & -0.56 \\
\hline 050050 (angina pectoris) & $68,777,051$ & $1,283,631$ & 1.87 & $76,811,532$ & $1,800,394$ & 2.34 \\
\hline 050070 (tachyarrhythmia) & $19,329,158$ & 227,492 & 1.18 & $18,254,244$ & $-123,544$ & -0.68 \\
\hline 050080 (valvular heart disease) & $24,243,458$ & $-1,039,821$ & -4.29 & $32,027,210$ & $-96,662$ & -0.30 \\
\hline 050130 (heart failure) & $12,503,913$ & 439,992 & 3.52 & $18,792,053$ & 848,201 & 4.51 \\
\hline 050170 (arteriosclerosis obliterans) & $6,226,082$ & $-159,658$ & -2.56 & $7,833,074$ & $-245,290$ & -3.13 \\
\hline 050210 (bradyarrhythmia) & 989,768 & 13,795 & 1.39 & 830,412 & $-6,928$ & -0.83 \\
\hline 100060 (diabetes mellitus, type 1) & 989,768 & 13,795 & 1.39 & 986,975 & $-1,910$ & -0.19 \\
\hline 100070 (diabetes mellitus, type 2) & $7,033,595$ & 277,510 & 3.95 & $11,601,112$ & $-118,953$ & -1.03 \\
\hline 100140 (hyperthyroidism) & $1,390,971$ & 104,148 & 7.49 & $2,130,503$ & 185,255 & 8.70 \\
\hline Total & $150,968,906$ & $1,095,002$ & 0.73 & $184,484,785$ & $2,155,856$ & 1.17 \\
\hline
\end{tabular}

Profits were calculated as DPC-FFS, and percentage profits as profits/DPC. One point is equivalent to 10 yen

diseases showed deficits in 2008. These deficits were covered by the profits of the 3 other diseases, angina pectoris, heart failure, and hyperthyroidism, resulting in an increase in total percentage profits in 2008.

\section{Discussion}

Introduction of the 7:1 system resulted in an increase in patient satisfaction and caused physicians and nurses to feel that their working hours had become shorter, whereas real working time was unaltered. In fact, the rate of physicians requiring care for Workload alone was significantly reduced under the $7: 1$ system, but the rates for other stressors were unaltered. The rates of nurses who required care were unaltered, and especially the rate of those requiring care for Workload remained higher than $90 \%$. The 7:1 system is an incentive for hospitals with introduction of DPC, but its effect was not obvious in terms of hospital benefit.

After introducing a new system/program, it is important to examine the quality management and the validity of the system/program to improve its quality. The Deming cycle (Shewhart cycle), known as the plan-do-study-act (PDSA)/plan-do-check-act (PDCA) paradigm [15], has been widely adopted worldwide, including in medical research/studies to test the effects and performance before and after the introduction of a new system/program [1618]. The DPC is newly introduced and, even though its study/check stage does not not yet seem to be sufficient, the new 7:1 system was introduced. It is necessary to study/ check details from both inside and outside. Generally, worker satisfaction is related to inpatient satisfaction [8]. For TQM, it is important to maintain the balance of worker quality of life and profits [16-18]. Therefore, the present study was performed to evaluate inpatient satisfaction and job satisfaction/stress of medical workers simultaneously. Moreover, the effects of the introduction of the 7:1 system on medical workers' estimation of the DPC function and on hospital profits were examined.

As DPC hospitals deal with patients with extremely serious conditions, it is not surprising that all SF-36 scores before hospitalization were lower than the national mean. Regardless of whether the patient was healthy or sick, scores in women are usually lower than those in men [5]. This was also true in the present study. Low scores in Physical Functioning, Role-Physical, etc., led to significantly lower scores in the Physical Component Summary for women as compared with men, suggesting restriction of female mobility. There was no significant difference in the Mental Component Summary between men and women, but the significantly lower scores in Vitality and RoleEmotional for women suggests occult mental health risk among female patients. Nonetheless, Satisfaction scores reached "somewhat satisfied," and therefore medical/ nursing care under the DPC seemed well organized. Higher scores in all satisfaction items examined under the 7:1 system than the 10:1 system showed that introduction of the 7:1 system was somewhat beneficial for inpatients. Low scores for Dealing with Patients and Easiness of Consultation in factor analysis confirmed that the 7:1 system increased the number and duration of nurses' rounds. A higher coefficient on multiple regression analysis for Nursing Care than for other types of care substantiated these findings. Physicians, who tended to be absent from the nurses' station, should be easily accessible and deal with and explain care to patients both reliably and sincerely. Although disease care was important, care by 
physicians was more important in terms of "mental" care than in terms of direct contact, such as Coping with Patients' Pain/Indisposition, which was usually considered to be Nursing Care rather than Medical Care.

In the 7:1 system, both physicians and nurses judged that their working hours had become significantly shorter than under the 10:1 system, although their real working hours were unaltered. The 7:1 system reduced the number of patients cared for by a single nurse at a time, whereas the time pressure due to shortened LOS continued, Therefore, the long working hours have not been improved for either physicians or nurses. Although the numbers of female physicians and male nurses are increasing, the majority of physicians and nurses are still male and female, respectively. Thus, nurses have heavier burdens at home than physicians, which may affect their estimation of Workload in a hospital/ward. However, more than $90 \%$ of nurses who required care in items of Workload in both systems showed no improvement in their workload in the 7:1 system. On the other hand, Personal Relations, Conformity, and Support by Coworkers/Supervisor for physicians and nurses were well administered regardless of the system, which may maintain a lower rate for those who required care for Mental and Physical Stress. This is a type of TQM performed by the workers themselves. However, the 7:1 system did not improve any of these qualities for either physicians or nurses. Moreover, the 7:1 system did not improve the Mental Stress of physicians or nurses, even though it slightly improved Physical Stress.

Understanding the DPC was categorized as "neither agree nor disagree" by the physicians and worse than "somewhat disagree" by the nurses, regardless of the nursing system. This was partly because some physicians and nurses only experienced the FFS at clinical training courses as a student, judging from their working years, and their knowledge about the differences between the FFS and DPC was limited. Even when they really did not know what type of system the DPC was, both physicians and nurses considered that introduction of the DPC could not always facilitate more efficient medical/nursing care, because all the scores were lower than "neither agree nor disagree." Under both systems, physicians had to spend almost $1 / 3$ of their working hours on paperwork/data input, so that the mean working $\mathrm{h} /$ week of the physicians in this hospital was similar to in other Japanese surveys [12-14, 19] and higher than in Organization for Economic Co-operation and Development (OECD) countries [20-22]. One of the major purposes of the DPC [23] was to shorten LOS. Both physicians and nurses did not judge LOS to be shorter or see an improvement in quality of medical/nursing care or in the working environment. Nonetheless, physicians tried to change the contents of medical care and the medicine/medical material.
Introduction of the 7:1 system is an incentive for hospitals introducing DPC to increase hospital profit but also causes an increase in the number of nurses needed, probably resulting in a deficit. Total profit of this hospital in 2008 increased compared with that in 2007. However, the percentage profit of 7 of 10 diseases became negative, and therefore this increase was dependent on the profit from the patients with the other 3 diseases, i.e., angina pectoris, heart failure, and hyperthyroidism. If the number of patients with these 7 diseases exceeded that with the other 3 diseases, the hospital would suffer a financial loss. Unfortunately, the profits under the DPC could be compared only with those under the FFS in the present study. As the DPC is new, there have not been many studies and surveys, so it is very difficult to confirm the appropriateness of the setting of the DPC coefficients and points to calculate medical expenses. It is unclear whether the current administration of a hospital/ward and/or clinical pass are suitable to such settings. These points should be taken into consideration for further evaluation of the DPC setting.

The 7:1 system showed advantages with regard to patient satisfaction, but not always for the QOL of the medical staff or hospital benefit, which are very important to maintain high quality of medical/nursing care. Physicians and nurses did not always understand what type of system the DPC was, and what was expected from the DPC. It will be necessary to educate staff regarding the importance of DPC for efficient implementation of this system. It is also important to further explore factors that will increase the QOL of medical workers and hospital income.

\section{References}

1. Ministry of Health, Labour and Welfare. Chuo Shakai Hokeniryou Kyougikai. http://www.mhlw.go.jp/shingi/0112/s1213-2c. html (2009). Accessed 10 Jan 2010 (in Japanese).

2. Miller RH, Luft HS. Managed care plans: characteristics, growth, and premium performance. Annu Rev Public Health. 1994;15: 437-59.

3. Stoddard JJ, Hargraves JL, Reed M, Vratil A. Managed care, professional autonomy, and income. J Gen Intern Med. 2001; 16(10):675-84.

4. Idezuki Y. Introduction of new payment system (DRG/PPS) to university hospitals. Nippon Geka Gakkai Zasshi. 2003;104: 312-9.

5. Yagihara Y. Influence of DPC on cardiovascular surgery. Nippon Geka Gakkai Zasshi 2005;106:641-4 (in Japanese).

6. Hamada Y. Effects and measures of the flat payment system based on the diagnosis procedure combination system in pediatric surgery. Nippon Geka Gakkai Zasshi 2005;106:654-8 (in Japanese).

7. Yasunaga H, Ide H, Imamura T, Ohe K. Impact of the Japanese Diagnosis Procedure Combination-based Payment System on cardiovascular medicine-related costs. Int Heart J. 2005;46(5): $855-66$. 
8. Yoshida K. Joy of work. Tokyo (Japan): Nikkei BP; 2005. p. 39-43 (in Japanese).

9. Fukuhara S, Suzukamo Y. Manual of SF-36v2 Japanese version. Kyoto: Institute for Health Outcomes \& Process Evaluation Research; 2004.

10. Council of Dean of Medical School and President of University Hospital, Japan. Investigation of quality, safety, and patients' satisfaction of University Hospitals through clinical indices. http:// www.umin.ac.jp/nuh_report/rinshou-shihyou.pdf (in Japanese).

11. Shimomitsu T. Job Stress Questionnaire. http://www.mhlw.go.jp/ shingi/2006/03/d1/s0327-2c.html (in Japanese).

12. Ministry of Health, Labour and Welfare. Chuo Shakai Hokeniryou Kyogikai. http://www.mhlw.go.jp/shingi/2006/03/d1/s0327-2c.html (in Japanese).

13. Ministry of Health, Labour and Welfare. Chuo Shakai Hokeniryou Kyogikai. http://www.mhlw.go.jp/shingi/2009/04/d1/s0422-4g.pdf (in Japanese).

14. Ministry of Health, Labour and Welfare. Chuo Shakai Hokeniryou Kyogikai. http://www.mhlw.go.jp/shingi/2009/04/dl/s0422-3c.pdf (in Japanese).

15. Walton M. The deming management method. New York (NY): A Perigee Book; 1986. p. 86-8.
16. Speroff T, James BC, Nelson EC, Headrick LA, Brommels M. Guidelines for appraisal and publication of PDSA quality improvement. Qual Manag Health Care. 2004;13:33-9.

17. Speroff T, O'Connor GT. Study designs for PDSA quality improvement research. Qual Manag Health Care. 2004;13:17-32.

18. Mori K, Takebayashi T. The introduction of an occupational health management system for solving issues in occupational health activities in Japan. Ind Health. 2002;40:167-74.

19. Lambert VA, Lambert CE, Ito M. Workplace stressors, ways of coping and demographic characteristics as predictors of physical and mental health of Japanese hospital nurses. Int Nurs Stud. 2004;41:85-97.

20. Bovier AP, Perneger VT. Predictors of work satisfaction among physicians. Euro J Public Health 2003;13(4):299-305.

21. Laubach W, Fischbeck S. Job satisfaction and the work situation of physicians: a survey at a German university hospital. Int Public Health. 2007;52:54-9.

22. OECD. OECD Health Data 2009-Version: November 09.

23. Ministry of Health, Labour and Welfare. Chuo Shakai Hokeniryou Kyogikai. http://www.mhlw.go.jp/shingi/2004/10/s1007-7b. html (in Japanese). 